\title{
Small molecule FGF receptor inhibitors block FGFR-dependent urothelial carcinoma growth in vitro and in vivo
}

\author{
FR Lamont', DC Tomlinson', PA Cooper², SD Shnyder², JD Chester' and MA Knowles*,' \\ 'Cancer Research UK Clinical Centre, Leeds Institute of Molecular Medicine, St James's University Hospital, Beckett Street, Leeds LS9 7TF, UK; ${ }^{2}$ Institute \\ of Cancer Therapeutics, University of Bradford, Richmond Road, Bradford BD7 IDP, UK
}

\begin{abstract}
BACKGROUND: Activating mutations of FGFR3 are frequently identified in superficial urothelial carcinoma (UC) and increased expression of FGFRI and FGFR3 are common in both superficial and invasive UC.

METHODS: The effects of inhibition of receptor activity by three small molecule inhibitors (PDI73074, TKI-258 and SU5402) were investigated in a panel of bladder tumour cell lines with known FGFR expression levels and FGFR3 mutation status.

RESULTS: All inhibitors prevented activation of FGFR3, and inhibited downstream MAPK pathway signalling. Response was related to FGFR3 and/or FGFRI expression levels. Cell lines with the highest levels of FGFR expression showed the greatest response and little or no effect was measured in normal human urothelial cells or in UC cell lines with activating RAS gene mutations. In sensitive cell lines, the drugs induced cell cycle arrest and/or apoptosis. IC 50 values for PDI73074 and TKI-258 were in the nanomolar concentration range compared with micromolar concentrations for SU5402. PDI73074 showed the greatest effects in vitro and in vivo significantly delayed the growth of subcutaneous bladder tumour xenografts.

CONCLUSION: These results indicate that inhibition of FGFRI and wild-type or mutant FGFR3 may represent a useful therapeutic approach in patients with both non-muscle invasive and muscle invasive UC.

British Journal of Cancer (20II) 104, 75-82. doi:I0.1038/sj.bjc.66060I6 www.bjcancer.com

Published online 30 November 2010

(c) 201। Cancer Research UK
\end{abstract}

Keywords: FGFR3; FGFRI; tyrosine kinase inhibitor; urothelial carcinoma; PDI73074; TKI-258

Urothelial carcinoma (UC) of the bladder is the fifth most common cancer in the developed world (Parkin et al, 2005) and can be divided into two groups, distinct at both the clinical and molecular level (Wu, 2005; Knowles, 2006). The first group, which at presentation represents $>50 \%$ of tumours, contains low-grade non-muscle invasive, papillary lesions (stage pTa and pT1) (WHO, 2004). Although this group has a high incidence of recurrence $(\sim 70 \%)$, progression to muscle invasion is not common $(10-20 \%)$ and prognosis is good (90\% survival at 5 years) (Holmang et al, 1995; Kurth et al, 1995). Standard treatment involves complete endoscopic resection of the tumour. However, residual malignant cells may remain and patients must be monitored for recurrence by regular cystoscopy, placing a huge burden on patients and health-care providers. Consequently bladder cancer is the most expensive cancer to treat (Sangar et al, 2005). For those tumours that are muscle invasive at diagnosis $(\sim 20 \%)$ there is a much poorer prognosis with $<50 \%$ survival at 5 years (Stein et al, 2001). These invasive tumours frequently progress to life-threatening metastasis, which, once clinically apparent, is associated with a 5-year survival rate of $6 \%$. The development of more effective therapies is required both to target residual tumour cells to prevent local recurrence via intravesical treatment of superficial UC and to provide more effective systemic therapy for invasive and metastatic tumours.

FGFR3 is a member of a family of four highly conserved transmembrane receptor kinases for the fibroblast growth factor (FGF) family of ligands, which have key roles in the regulation of

*Correspondence: Dr MA Knowles; E-mail: m.a.knowles@leeds.ac.uk Revised 22 October 2010; accepted 28 October 20I0; published online 30 November 2010 cell proliferation, differentiation and tumorigenesis. Mutation of FGFR3 is the most common genetic alteration in superficial UC (Cappellen et al, 1999; Billerey et al, 2001; Sibley et al, 2001a), and is strongly associated with low tumour grade and stage (Billerey et al, 2001; Kimura et al, 2001; van Rhijn et al, 2001). Mutations result in constitutive activation of the receptor (Ornitz and Itoh, 2001). FGFR3 protein expression is strongly related to mutation status, with increased expression in the majority of FGFR3-mutant superficial tumours (Tomlinson et al, 2007a). Increased FGFR3 signalling may also be achieved via overexpression of the wild-type receptor and $>40 \%$ of muscle invasive bladder tumours have been found to overexpress wild-type FGFR3 protein (Tomlinson et al, 2007a), suggesting a role for mutant FGFR3 predominantly in superficial UC and a role for overexpression of wild-type FGFR3 in invasive UC. Overexpression of wild-type FGFR1 is also common in UC of all grades and stages (Tomlinson et al, 2009). Therefore, FGFR1 and both wild-type and mutant forms of FGFR3 may be valid therapeutic targets in invasive and non-invasive UC.

The only other tumour type in which FGFR3 has a significant role is multiple myeloma (MM). The $t(4 ; 14)$ (p16.3;q32) translocation found in these malignancies results in dysregulated FGFR3 expression in about 15-20\% of patients (Chesi et al, 1997, 1998; Keats et al, 2003; Santra et al, 2003). Approximately $10 \%$ of cases with translocation acquire an activating mutation (Intini et al, 2001), which contributes to tumour progression (Chesi et al, 2001). Inhibition of FGFR3 has been effective in preclinical studies of MM. Small molecule inhibitors and neutralising antibodies induce cytotoxicity and inhibit proliferation in FGFR3-expressing MM cells both in vitro and in vivo (Grand et al, 2004; Paterson et al, 2004; Trudel et al, 2004, 2005, 2006; Chen et al, 2005; Xin et al, 2006). 
Mutant FGFR3 has been validated in vitro as a potential therapeutic target in bladder cancer, by siRNA knockdown of the most common mutant forms, S249C and Y375C (Bernard-Pierrot et al, 2006; Tomlinson et al, 2007b). Targeted inhibition by neutralising antibodies also results in reduced proliferation of UC cell lines expressing high levels of wild-type FGFR3 (GomezRoman et al, 2005; Martinez-Torrecuadrada et al, 2005). Recently, confirmation of an oncogenic role for FGFR3 in UC in vivo has come from the use of inducible shRNA knockdown to inhibit UCderived xenografts and from antibody-based selective inhibition of FGFR3 in human UC cell line xenografts with either overexpression of wild-type or mutant FGFR3 (Qing et al, 2009).

Further examination of the effects of FGFR inhibitors in preclinical models in vivo is required to confirm that dependence on FGFR1 and both wild-type and mutant FGFR3 in culture models can be translated into therapeutic efficacy. As normal urothelial cells express FGFR3 and a potential negative regulatory effect on their proliferation has been suggested (Tomlinson et al, 2005), examination of the effects of targeted agents on these cells is required. Here, we have evaluated the in vitro and in vivo effects of FGFR1 and FGFR3 inhibition in a panel of normal urothelial cells and bladder tumour cell lines with known FGFR mutation and expression status using three small molecule inhibitors, with known activity against FGFRs.

\section{MATERIALS AND METHODS}

\section{Cell lines and reagents}

Thirteen bladder tumour cell lines were used: FGFR3 mutant cell lines (97-7, 97-18, 94-10, J82 and MGH-U3), non-mutant cell lines (RT4, RT112, SW780 and JMSU1) and cell lines that are wild-type for FGFR3 but have an activating RAS mutation (T24, UM-UC3, KU-19-19 and HT1197). All lines have been authenticated in our laboratory by extensive genomic analysis (microsatellite typing, conventional karyotypic analysis, MFISH, array-based copy number analysis and mutation analysis) within the last 12 months. Cells were grown in standard media at $37{ }^{\circ} \mathrm{C}$ in $5 \% \mathrm{CO}_{2}$. Normal human urothelial cells (NHUCs) were derived from urothelium stripped from human ureters obtained at nephrectomy (Southgate et $a l, 1994)$ and maintained in keratinocyte growth medium supplemented with epidermal growth factor and bovine pituitary extract (PromoCell, Sickingenstr, Germany). Two lines of telomeraseimmortalised NHUC (TERT-NHUC) were also used (Chapman et al, 2006). For FGF2 stimulation experiments cells were treated with $5 \mathrm{ng} \mathrm{ml}^{-1}$ recombinant human FGF2 and $10 \mu \mathrm{g} \mathrm{ml}^{-1}$ heparin (R\&D Systems Europe Ltd, Abingdon, UK).

\section{Kinase assays}

The $\mathrm{IC}_{50}$ values for inhibition of FGFR1 and FGFR3 by PD173074 (Sigma, Poole, Dorset, UK), TKI-258 (Selleck Chemicals, London, ON, Canada) and SU5402 (Calbiochem, supplied by Merck Chemicals, Nottingham, UK) were determined using a FRETbased in vitro kinase assay (Z'-lyte assay, Invitrogen, Paisley, UK). The kinase domains of FGFR1 or FGFR3 were assayed in $50 \mathrm{~mm}$ HEPES pH 7.5, 0.01\% BRIJ-35, $10 \mathrm{mM} \mathrm{MgCl}_{2}, 2 \mathrm{mM} \mathrm{MnCl}_{2}, 1 \mathrm{mM}$ EGTA, $1 \mathrm{~mm}$ DTT, with $20 \mu \mathrm{m}$ or $80 \mu \mathrm{M}$ ATP, respectively. The assay was performed in triplicate in 384-well plates according to the manufacturer's instructions.

\section{Adherent and viable cell counts}

Cells were plated in six-well plates and adherent cells counted using a Z2 Coulter Particle Counter and Size analyser (Beckman Coulter, High Wycombe, Buckinghamshire, UK). Viable cells were stained using the Guava PCA-96 ViaCount Flex Reagent and analysed on the Guava Easycyte Desktop Flow Cytometry System (Guava Technologies, Stamford, Lincolnshire, UK).

\section{Cell viability assay}

Cell viability was assessed by 3-(4,5-dimethylthiazol)-2,5-diphenyl tetrazolium (MTT) assay. In all, 3000 cells per well were plated in 96-well plates in quadruplicate and allowed to attach for $24 \mathrm{~h}$ before addition of inhibitor. Medium was replenished with fresh drug after $48 \mathrm{~h}$ and the MTT assay performed $72 \mathrm{~h}$ later. In total, $10 \mu \mathrm{l}$ of $5 \mathrm{mg} \mathrm{ml}^{-1}$ MTT solution was added to the medium for $4 \mathrm{~h}$, the medium was removed, the precipitate dissolved in DMSO and absorbance read at $540 \mathrm{~nm}$.

\section{Cell cycle and apoptosis analysis}

Cell cycle distribution of cells cultured with $500 \mathrm{~nm}$ PD173074, 500 nM TKI-258 or DMSO was evaluated by flow cytometry. Cells were harvested, fixed overnight in $70 \%$ ethanol at $4{ }^{\circ} \mathrm{C}$, rehydrated by addition of $10 \mathrm{ml}$ phosphate-buffered saline $(\mathrm{pH} \mathrm{7.4)}$ and centrifuged at $450 \times \mathrm{g}$ for $10 \mathrm{~min}$. The pellet was resuspended in propidium iodide/RNAse mix (Beckman Coulter) and incubated in the dark at $37^{\circ} \mathrm{C}$ for 30 min before analysis on the Guava Easycyte Desktop Flow Cytometry System. For apoptosis analysis cells were stained using a Guava-96 Nexin Kit.

\section{Western blotting and immunoprecipitation}

Cells were lysed in RIPAE buffer ( $1 \%$ Triton X-100, $1 \mathrm{mmoll}^{-1}$ EDTA, $0.1 \%$ SDS, $0.5 \%$ sodium deoxycholate, $10 \%$ glycerol, and protease inhibitor cocktail (Sigma) in PBS) and lysates cleared by centrifugation at $12700 \times \mathrm{g}$ at $4{ }^{\circ} \mathrm{C}$. Protein concentrations were determined using the bicinchonic acid assay (Thermo Fisher Scientific, Runcorn, Cheshire, UK). Western blotting and immunoprecipitation was carried out as described previously (Tomlinson et al, 2009). FGFR3 was immunoprecipitated using an FGFR3 antibody recognising the extracellular domain (F3922, Sigma). Antibodies used for western blotting were anti-phospho-ERK1/2, anti-ERK1/2 (Santa Cruz Biotechnology, Santa Cruz, CA, USA), FGFR3 B9 (Autogen Bioclear, Calne, Wiltshire, UK), 4G10 antiphosphotyrosine (Cell Signalling Technology, Danvers, MA, USA) and anti-tubulin alpha (MorphoSys UK Ltd, Kidlington, UK). Proteins were visualised with chemiluminescence (ECL Plus Kit, Amersham Biosciences, Little Chalfront, Buckinghamshire, UK).

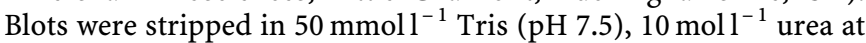
$55^{\circ} \mathrm{C}$ for $30 \mathrm{~min}$ before re-probing.

\section{Animals}

Male Balb/c immunodeficient nude mice (Harlan, Loughborough, UK) aged 6-8 weeks were used. Mice received Harlan 2018 diet (Harlan) and water ad libitum. Mice were kept in cages in an airconditioned room with regular alternating cycles of light and darkness. All animal procedures were carried out under a project licence issued by the UK Home Office and UKCCCR guidelines (Workman et al, 1998) were followed throughout.

Xenografts were established by subcutaneous inoculation of MGH-U3, SW780 or RT112 cells. Tumours were excised from a donor animal, cut into fragments of approximately $2 \mathrm{~mm}^{3}$ and single fragments implanted into the left abdominal flanks of recipient mice under brief general anaesthesia using a trocar. Once the tumours could be accurately measured (mean tumour volume of $32 \mathrm{~mm}^{3}$ ), mice were allocated into groups of eight (for each tumour type and condition) by restricted randomisation to keep group mean tumour size variation to a minimum and treatment was commenced. Groups consisted of an untreated control group and a PD173074-treated group. PD173074 was administered 
intraperitoneally at $20 \mathrm{mg} \mathrm{kg}^{-1}$ per day on days $0-3$ (all tumour types), and days 6-9 (MGH-U3 only).

The effects of therapy were assessed by two-dimensional caliper measurement. Tumour volumes were calculated using the formula $D \times d^{2} \times \pi / 6$ where $D$ is the larger and $d$ is the smaller diameter of the tumour. Tumour volume was normalised to the volume on day 0 . Statistical significance was assessed by Mann-Whitney $U$-test. A $P$-value of $<0.05$ was considered statistically significant.

\section{Immunohistochemistry}

Tumours were formalin-fixed and embedded in paraffin wax. Sections $(4 \mu \mathrm{m})$ were stained with haematoxylin and eosin. Antigen retrieval was achieved by boiling with citric acid buffer $(10 \mathrm{~mm}$ citric acid; $\mathrm{pH} 6$; $\mathrm{BDH}$ ) for $12 \mathrm{~min}$. The proliferation-associated Ki-67 protein was used to identify proliferative cell populations, using mouse anti-human Ki-67 antibody (Dako, Produktionsvej, Denmark) at a 1:100 dilution. Ki-67 staining was detected using streptavidin $\mathrm{AB}$ (Dako) and 3,3-diaminobenzidine (Dako). Sections were counterstained with Mayer's haematoxylin. Sections were observed by light microscopy (Zeiss Axioplan; Carl Zeiss UK, Welwyn Garden City, Hertfordshire, UK). Cells were defined as proliferative when nuclear brown staining was observed. The terminal deoxynucleotidyl transferase-mediated dUTP nick-end labelling (TUNEL) assay (ApopTag Plus Peroxidase In situ Apoptosis Detection Kit; Millipore, Watford, Hertfordshire, UK) was used for detection and quantitation of apoptosis at the singlecell level, labelling DNA strand breaks. Cells were defined as apoptotic (TUNEL-positive) if nuclear localised brown staining was observed. Proliferation and apoptotic indices were scored as the percentage of positive cells in four fields of view from three different sections from the same tumour (original magnification $\times 200$ ). Two to three tumours from each tumour type and condition were analysed in this way.

\section{RESULTS}

\section{PD173074, TKI-258 and SU5402 inhibit FGFR3 phosphorylation and downstream signalling}

Numerous inhibitors of FGFR activation have been identified. Here, we assessed two FGFR-selective inhibitors, PD173074 (Mohammadi et al, 1998) and SU5402 (Mohammadi et al, 1997) and a broad-spectrum tyrosine kinase inhibitor, TKI-258, with known activity against FGFRs (Lee et al, 2005; Lopes de Menezes et al, 2005; Trudel et al, 2005). Their reported activity against receptor tyrosine kinases is shown in Supplementary Table 1. We confirmed the effect on FGFR3 and FGFR1 kinase activity using an in vitro kinase assay. All three compounds caused a dose-dependent reduction in kinase activity (Supplementary Figure 1). RT112 cells show constitutive activation of FGFR3 and were used to assess the effects of PD173074, SU5402 and TKI-258 on FGFR3 phosphorylation and downstream signalling (Figure $1 \mathrm{~B}$ and $\mathrm{C}$ ). A time-course of treatment with PD173074 showed a rapid and sustained inactivation of FGFR3 (Figure 1B). After $2 \mathrm{~h}$ of treatment, all inhibitors showed profound inhibition of FGFR3 phosphorylation. Recently, we have shown that FGFR3 activates the MAPK pathway in normal urothelial cells (di Martino et al, 2009). Thus, the effect of treatment on phosphorylation of ERK was assessed and all three drugs were found to reduce ERK activation (Figure 1C). In addition, PD173074 was found to block both FGF-induced and constitutive ERK phosphorylation in 94-10 tumour cells, confirming that PD173074 prevents FGFR-induced ERK activation and is not acting by some other mechanism (Figure 1A).

\section{Effects of inhibitors on proliferation and viability of bladder tumour cells}

We assessed the effect of the inhibitors on a panel of bladder tumour cell lines with known FGFR3 and RAS mutation status (Jebar et al, 2005, unpublished data) (Table 1). We also determined the transcript levels of FGFRs 1-4 in these cell lines. Expression of FGFRs 2 and 4 was extremely low in all lines (data not shown) but highly variable levels of FGFR1 and FGFR3 transcripts (a range of 5-6 logs) were detected (Supplementary Figure 2). Cells were cultured with a range of concentrations of each inhibitor for 5 days $(0-2000 \mathrm{nM}$ PD173074; $0-1000 \mathrm{nM}$ TKI-258; 0-50 $\mu \mathrm{M}$ SU5402). Responses were measured by changes in cell number, shown here for PD173074 (Figure 1D). A dosedependent reduction in cell number was observed. Cell viability analysis by MTT assay gave similar results. Dose-response curves were created for all cell lines and all three inhibitors (data not shown) and were used to determine $\mathrm{IC}_{50}$ values (Table 1). All three compounds inhibited proliferation and viability of three of the five FGFR3 mutant and all four FGFR3 wild-type cell lines. PD173074 and TKI-258 were most potent, with $\mathrm{IC}_{50}$ values in the nanomolar range, whereas micromolar concentrations of SU5402 were required to achieve the same effect.
A

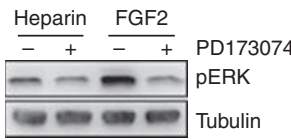

B

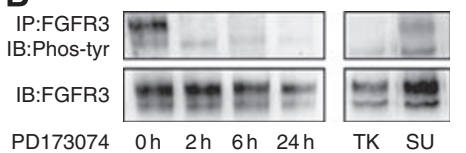

C

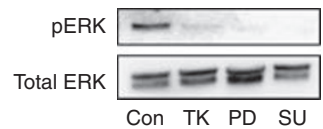

D

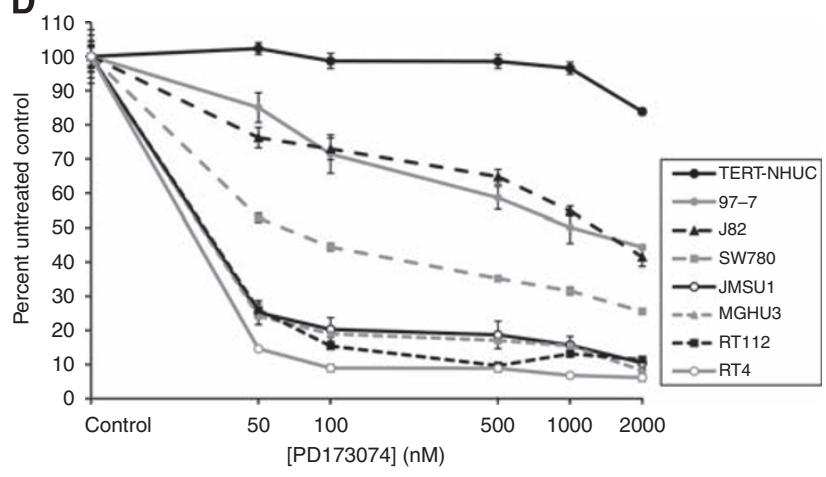

Figure I The effect of PDI73074 on FGFR3 phosphorylation and proliferation of FGFR3-expressing bladder tumour cell lines. (A) 94 - I0 cells, expressing FGFRI, were stimulated with heparin $\left(10 \mu \mathrm{g} \mathrm{m}^{-1}\right)$ with or without FGF2 $\left(5 \mathrm{ng} \mathrm{ml}^{-1}\right)$ for $15 \mathrm{~min}$ in the presence or absence of PDI73074 (500 nM; pretreated for I h). Cells were lysed, immunoblotted for phospho-ERK and reprobed for tubulin as a loading control. (B) RTII2 cells were exposed to PDI73074 (PD) (500 nM) for 0-24h, TKI-258 (TK) (500 nM) or SU5402 (SU) (5 $\mu \mathrm{M})$ for I h. Cells were lysed, FGFR3 was immunoprecipitated (immunoprecipitated, IP) and blots (immunoblot, IB) were probed for phospho-tyrosine and reprobed for FGFR3 or (C) probed for phospho-ERK and reprobed for total ERK. (D) Cells were exposed to 0-2000 nM PDI73074 for 5 days and the effects analysed by cell counts. Values are represented as a percentage of the untreated control (I00\%) and represent mean \pm I s.d. 
Table I IC 50 values for PDI73074, TKI-258 and SU5402 following 5-day treatment of bladder tumour cell lines and normal urothelial cells

\begin{tabular}{|c|c|c|c|c|c|}
\hline \multirow[b]{2}{*}{ Cell line type } & \multirow[b]{2}{*}{ Cell line } & \multirow[b]{2}{*}{ FGFR3 status/expression level } & \multicolumn{3}{|c|}{$1 C_{50}(\mathrm{nM})$} \\
\hline & & & PDI73074 & TKI-258 & SU5402 \\
\hline \multirow[t]{3}{*}{ Normal controls (WT FGFR3) } & NHUC & WT & $>2000$ & 2000 & $>50000$ \\
\hline & TERT-NHUC B & WT & $>2000$ & 900 & 50000 \\
\hline & TERT-NHUC D & WT & $>2000$ & 650 & - \\
\hline \multirow[t]{4}{*}{ Tumour lines (WT FGFR3+mutant RAS) } & UM-UC3 & WT & $>2000$ & $>2000$ & $>50000$ \\
\hline & $\mathrm{T} 24$ & WT & $>2000$ & $>2000$ & $>50000$ \\
\hline & $K \cup-19-19$ & WT & $>2000$ & $>2000$ & $>50000$ \\
\hline & HTI।97 & $\mathrm{WT}$ & $>2000$ & 1000 & $>45000$ \\
\hline \multirow[t]{4}{*}{ Tumour lines (WT FGFR3) } & SW780 & WT overexpressed & 50 & 450 & 6000 \\
\hline & RTII2 & WT overexpressed & 15 & 200 & 6000 \\
\hline & RT4 & WT overexpressed & 5 & 100 & 2000 \\
\hline & JMSUI & WT low expression + FGFRI overexpressed & 50 & 250 & 40000 \\
\hline \multirow[t]{5}{*}{ Tumour lines (Mutant FGFR3) } & 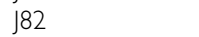 & K652E low expression + FGFRI overexpressed & 1400 & 1000 & 45000 \\
\hline & $\mathrm{MGH}-\mathrm{U} 3$ & Y375C overexpressed & $<50$ & $<50$ & 6000 \\
\hline & $97-7$ & S249C overexpressed & 1000 & 800 & 25000 \\
\hline & $94-10$ & S249C low expression & $>2000$ & $>2000$ & - \\
\hline & $97-18$ & S249C low expression & $>2000$ & $>2000$ & - \\
\hline
\end{tabular}

Abbreviations: NHUC = normal human urothelial cell; TERT-NHUC = telomerase-immortalised NHUC.

Responses appeared to be related to FGFR3 and FGFR1 expression levels. FGFR3-mutant cell lines that were totally unresponsive to treatment (97-18 and 94-10, which exhibited high $\mathrm{IC}_{50}$ values for all compounds; Table 1) expressed little or no FGFR3 (see Supplementary Figure 2 for expression levels) and may therefore no longer depend on its activity. One of the responsive cell lines, JMSU1, which does not express FGFR3, overexpresses FGFR1 and we have shown previously that siRNA-mediated knockdown of FGFR1 inhibits proliferation of these cells (Tomlinson et al, 2009). J82, also a non-expresser of FGFR3, showed only a small response ( $\mathrm{IC}_{50}$ for PD173074 of $1400 \mathrm{nM}$ ). These cells express FGFR1, albeit at lower levels than JMSU1 (Supplementary Figure 2). The only other cell lines in this panel that express high levels of FGFR1 are the RAS mutant cell lines UM-UC3 and HT1197. As activating mutations of RAS genes and FGFR3 are mutually exclusive events in UC and are thought to activate the same signalling pathways (Jebar et al, 2005), a RAS mutation may confer resistance to FGFR inhibition. Indeed, all four cell lines with an activating RAS mutation were unaffected by PD170374 or SU5402 treatment and we have shown previously that siRNA-mediated knockdown of FGFR1 in UM-UC3 has no effect on proliferation (Tomlinson et al, 2009). PD173074 and SU5402 had no effect on the normal TERT-NHUC control cells. TKI-258 had some inhibitory activity on these controls and the RAS mutant tumour control cell line HT1197, which may reflect the multitargeted nature of this inhibitor.

Despite profound inhibition of cell proliferation in some cell lines, total cell-kill was not achieved and there was always a small population of viable cells remaining after treatment. To test whether these surviving cells represent a sub-population of resistant cells, we compared the response of previously untreated RT112 cells with those that had been previously exposed to drugs (Supplementary Figure 3). Almost identical responses were observed, demonstrating that a resistant population was not present. Owing to the presence of viable cells following treatment at all doses, continuous exposure to all compounds was required to elicit and maintain a response.

\section{Growth inhibition is associated with cell cycle arrest and apoptosis}

As PD173074 and TKI-258 were the most potent compounds, with nanomolar $\mathrm{IC}_{50}$ values, these were used for further mechanistic studies. To examine whether responses in FGFR3-expressing cells were mediated by cytostatic or cytotoxic effects, responsive cells (RT112, RT4, SW780, MGH-U3 and 97-7) were analysed for cell cycle distribution and apoptosis. A significant increase in the proportion of cells in $G_{1}$ accompanied by a decrease in $S$ and $G_{2} / M$ phases was observed in PD173074- and TKI-258-treated RT112, RT4, MGH-U3 and 97-7 cells after 24-h exposure (Figure 2A). This effect was more pronounced with PD170374 treatment. SW780 showed no significant change in cell cycle distribution. SW780, RT4 and MGH-U3 showed an increased apoptotic index after 2-5 days treatment with PD173074 or TKI-258 (Figure 2B). There was no change in the proportion of apoptotic cells in any other cell lines over a 5 -day time-course.

\section{PD173074 delays tumour growth in vivo}

We selected PD173074 for in vivo assessment as it was the most potent and selective compound, with the lowest $\mathrm{IC}_{50}$ values and the most pronounced cell cycle and apoptotic effects in vitro. We tested efficacy on pre-established subcutaneous xenografts of MGH-U3, which contains Y375C-FGFR3, and RT112 and SW780 both of which are non-mutant but have upregulated expression of FGFR3 (Figure 3). No evidence of significant toxicity was seen in the treated animals. Treatment significantly delayed tumour growth for all cell lines. Tumours were retrieved and fixed following the final PD170374 treatment and sections stained for Ki-67 and TUNEL to assess effects on proliferation and apoptosis respectively. Decreased proliferative index (Figure 3) but no change in apoptotic index were found in all three cell lines (Supplementary Figure 4). This suggests that FGFR3 inhibition induces a cytostatic response in vivo.

\section{DISCUSSION}

It is well documented that activating mutations of FGFR3 are strongly associated with superficial UC (Cappellen et al, 1999; Billerey et al, 2001; Sibley et al, 2001b). More recently, overexpression of wild-type FGFR3 has also been found in UC, particularly in tumours of high grade and stage (Tomlinson et al, 2007a). FGFR3-targeted therapies, small molecule inhibitors and neutralising antibodies, have been used successfully in MM to inhibit the proliferation of cell lines in vitro and in vivo, inducing cell cycle arrest, apoptosis and differentiation (Grand et al, 2004; Paterson et al, 2004; Chen et al, 2005; Trudel et al, 2005, 2006; 

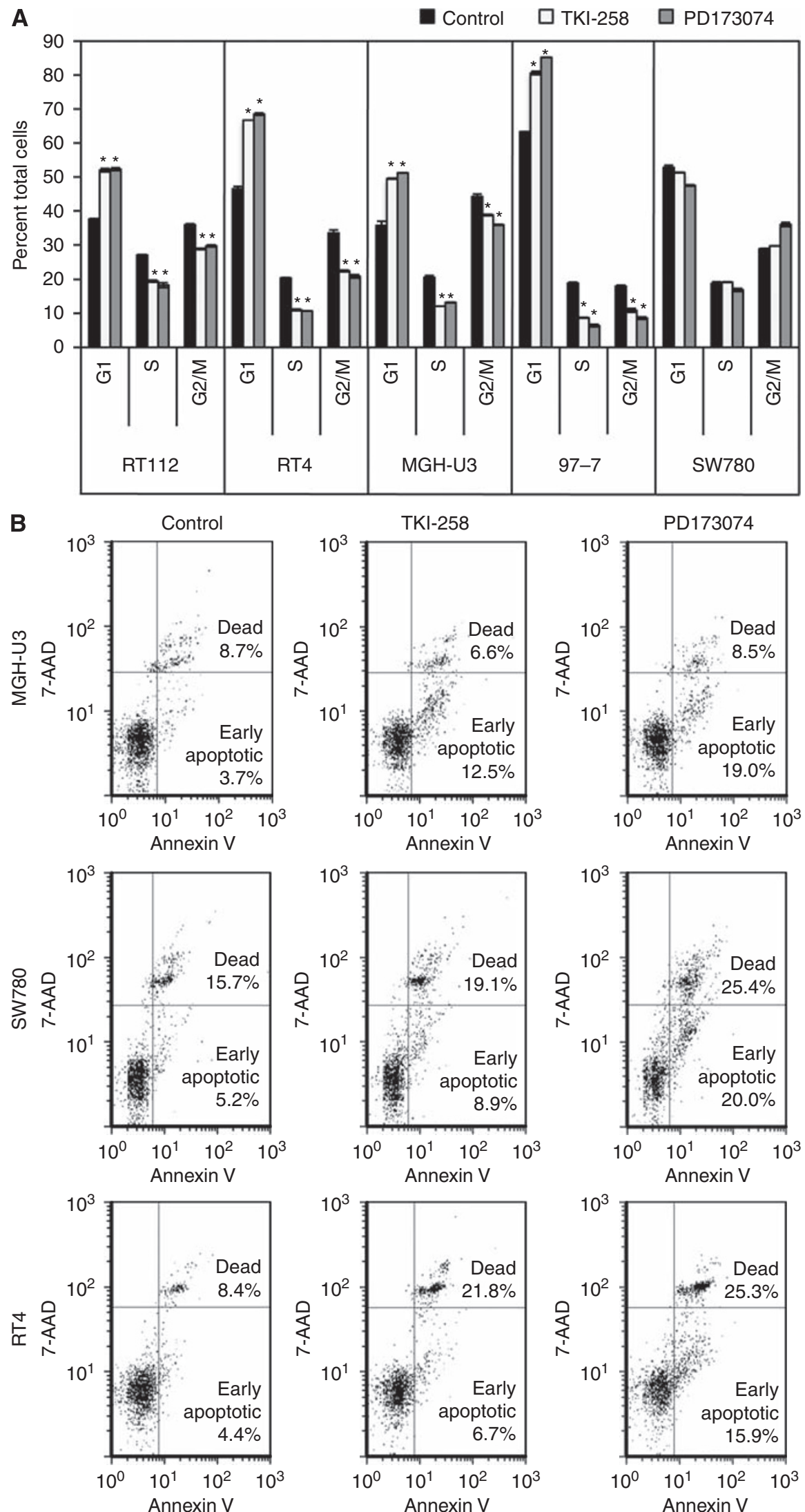

Figure 2 Effect of exposure to PD I 73074 or TKI-258 on cell cycle distribution and apoptosis. (A) Cells were exposed to PD I 73074 or TKI-258 (500 nM) for $24 \mathrm{~h}$. Cell cycle profile was analysed using the Guava Easycyte Plus flow cytometry system. ANOVA, *P $<0.05$. Data are representative of three independent experiments. (B) Effect of PDI73074 on apoptosis. Cells were exposed to PDI703074 (500 nM) for 6 days and were analysed for apoptosis using the Guava Nexin assay. 7-AAD, 7-amino-actinomycin-D. Plots are representative of three independent experiments. 
A
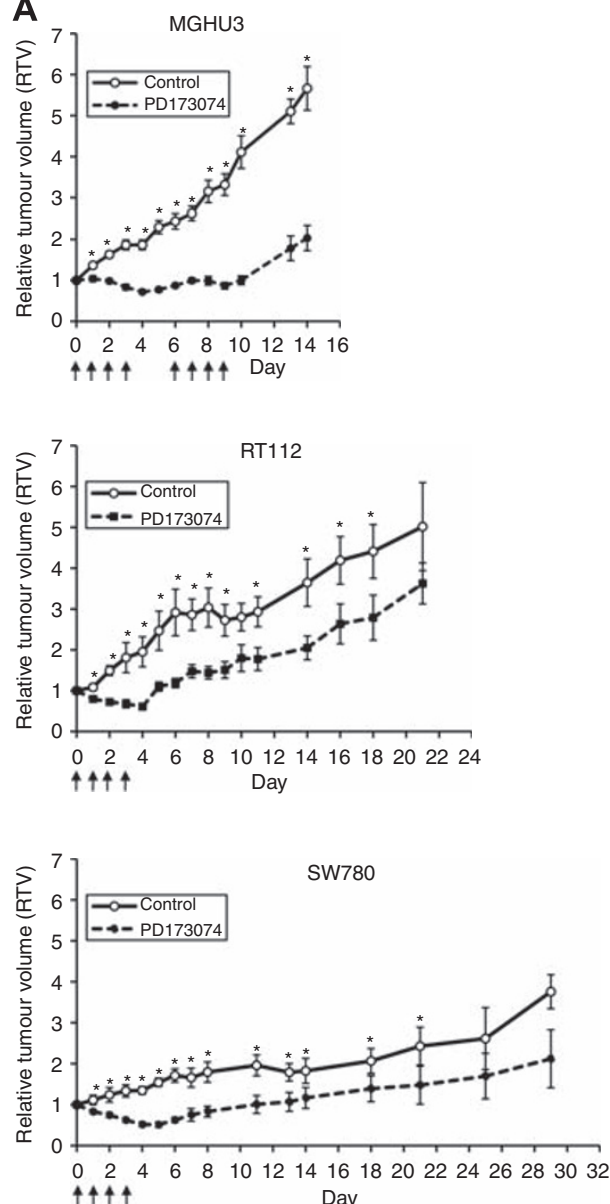

B
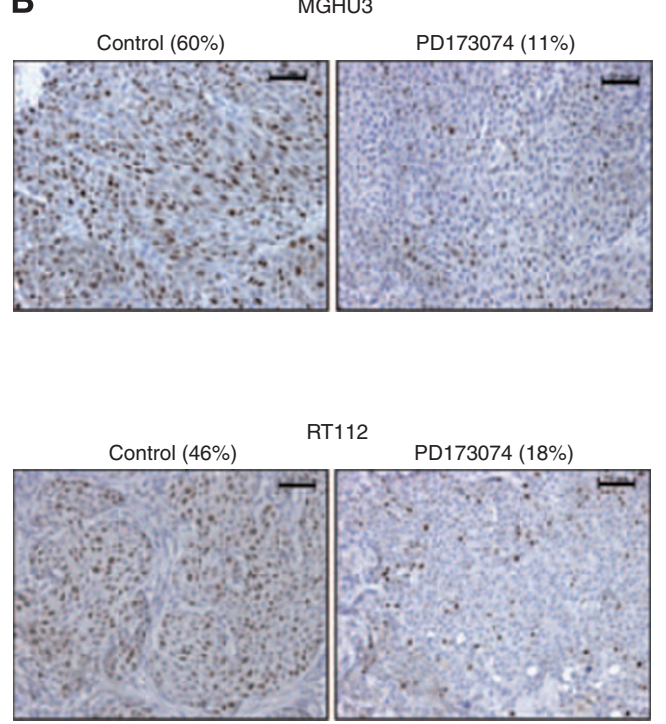

SW780

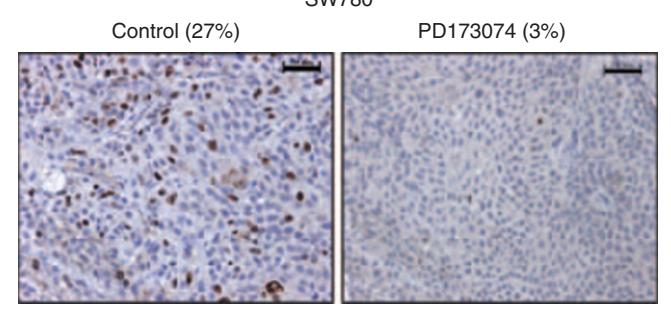

Figure 3 Effect of PDI73074 on the growth of subcutaneous xenografts. Xenografts were created by inoculating with MGH-U3, RTII2 or SW780 bladder tumour fragments ( $2 \mathrm{~mm}^{3}$ fragments). (A) PDI73074 $\left(20 \mathrm{mg} \mathrm{kg}^{-1}\right)$ was administered by intraperitoneal (i.p.) injection, indicated by black arrows. Tumours were measured at least three times a week and relative tumour volume calculated $(* P<0.05$; ANOVA). (B) Tumours were retrieved following the final dose of PDI70374, fixed and stained for Ki-67 and proliferative index calculated. Bar $=50 \mu \mathrm{m}$.

Xin et al, 2006; Qing et al, 2009). Several studies have assessed the most common FGFR3 mutations, S249C and Y375C, as therapeutic targets in UC cell lines (Bernard-Pierrot et al, 2006; Tomlinson et al, 2007b; Miyake et al, 2009; Qing et al, 2009) and have shown that suppression of FGFR3 activity results in inhibition of proliferation in vitro. The in vivo potential of FGFR3-targeted therapies in UC has also been assessed in two recent studies using xenografted human UC cell lines (Miyake et al, 2009; Qing et al, 2009). Qing et al (2009) used shRNA knockdown and a newly developed antibody that prevents both ligand binding and receptor dimerisation and showed inhibition of RT112 xenograft tumour growth. Miyake et al (2009) used two different FGFR3-mutant cell lines (UMUC14, MGH-U3), both of which showed growth delay when treated with PD173074. However, the effects of FGFR inhibitors have not been tested on FGFR1-dependent urothelial cells.

Using small molecule inhibitors, we have extended these findings using a range of both normal and UC-derived cell lines in vitro and UC xenografts in vivo. Importantly, there was an encouraging differential between the sensitivities of NHUCs and bladder tumour cell lines. Normal human urothelial cells and TERT-NHUC were unresponsive to treatment with high doses of inhibitors, demonstrating that these cells are not dependent on FGFR signalling for survival and predicting minimal toxicity to normal urothelial cells in vivo. This may be of particular importance if high levels of inhibitors are delivered intravesically in the future.
The effects of the inhibitors were related to FGFR3 expression levels. Thus, cell lines that express only low levels of mutant receptor were unresponsive to treatment, whereas cell lines that overexpress wild-type or mutant FGFR3 were highly sensitive to treatment. Cell lines that were unresponsive to FGFR inhibition may no longer depend on FGFR3, despite the presence of a mutation. Indeed, we have found previously that $15 \%$ of tumours with an FGFR3 mutation do not show upregulated protein expression (Tomlinson et al, 2007a). This may represent a subset for whom FGFR-targeted therapy is inappropriate.

As all three inhibitors have activity against all FGF receptors, inhibition of other FGFRs may have contributed to a response. Recently, FGFR1 has been identified as a potential therapeutic target that drives proliferation and cell survival in UC (Tomlinson et al, 2009). We showed that the cell line JMSU1 that expresses high levels of FGFR1 was sensitive to treatment. The smaller response measured in $\mathrm{J} 82$ could be also related to its moderate expression of FGFR1. We previously showed that shRNA knockdown of FGFR1 in JMSU1 results in inhibition of proliferation, indicating that these cells are highly dependent on FGFR1 and may exhibit an 'oncogene addiction' to this receptor (Tomlinson et al, 2009).

All three small molecule inhibitors have some activity against other receptor tyrosine kinases. Therefore, we cannot rule out the possibility that inhibition of other proteins may have contributed to their response. However, as similar trends were seen with all three inhibitors, each with different selectivity profiles, and 
because our findings so closely mimic those of others in MM and in bladder cancer, using similar or more specific means of FGFR3 inhibition, we can be reasonably confident that responses are due to FGFR inhibition rather than contribution from other kinases.

Cell lines that harbour an activating RAS mutation were included in the panel as controls, as these are predicted to be independent of FGFR signalling. FGFR3 and RAS mutations are mutually exclusive events in UC and in MM and are thought to provide alternative means to activate the same pathway (Plowright et al, 2000; Jebar et al, 2005). Similarly, MM cell lines with an activating RAS mutation have been shown to be resistant to FGFR3 inhibition. The differential responses of the bladder tumour cell lines may therefore reflect the distinct genetic make-up and FGFR3 dependence of individual tumours. Clinically, FGFR-targeted therapies are likely to be suitable only for patients whose tumours are still driven by FGFR3 and/or FGFR1 kinase activity. Our finding of resistance to targeted agents in the presence of FGFR3 mutation underscores the need to use biomarkers of FGFR dependence rather than mutation status when selecting patients for therapy in the future. Our present findings indicate that upregulated expression with or without mutation may be a useful indicator.

In vitro analysis showed that FGFR3 inhibition by PD173074 and TKI-258 was associated with cell cycle arrest, with evidence of apoptosis in some cell lines. The molecular basis for this differential response is not known but ability to induce apoptosis may not be related solely to p53 status as the highly sensitive cell lines RT112 and RT4, only one of which showed an apoptotic response, are both known to retain wild-type TP53.

PD173074 halted the growth of human bladder tumour xenografts derived from cell lines that overexpress wild-type (RT112 and SW780) or Y375C-mutant FGFR3 (MGH-U3). In all cases, tumour growth resumed following withdrawal of treatment. PD173074 treatment in vivo was associated with cell cycle arrest as

\section{REFERENCES}

Bernard-Pierrot I, Brams A, Dunois-Larde C, Caillault A, Diez de Medina SG, Cappellen D, Graff G, Thiery JP, Chopin D, Ricol D, Radvanyi F (2006) Oncogenic properties of the mutated forms of fibroblast growth factor receptor 3b. Carcinogenesis 27: 740-747

Billerey C, Chopin D, Aubriot-Lorton MH, Ricol D, Gil Diez de Medina S, Van Rhijn B, Bralet MP, Lefrere-Belda MA, Lahaye JB, Abbou CC, Bonaventure J, Zafrani ES, van der Kwast T, Thiery JP, Radvanyi F (2001) Frequent FGFR3 mutations in papillary non-invasive bladder ( $\mathrm{pTa}$ ) tumors. Am J Pathol 158: 1955-1959

Cappellen D, De Oliveira C, Ricol D, de Medina S, Bourdin J, Sastre-Garau X, Chopin D, Thiery JP, Radvanyi F (1999) Frequent activating mutations of FGFR3 in human bladder and cervix carcinomas. Nat Genet 23: 18-20

Chapman EJ, Hurst CD, Pitt E, Chambers P, Aveyard JS, Knowles MA (2006) Expression of hTERT immortalises normal human urothelial cells without inactivation of the $\mathrm{p} 16 / \mathrm{Rb}$ pathway. Oncogene 25: 5037-5045

Chen J, Lee BH, Williams IR, Kutok JL, Mitsiades CS, Duclos N, Cohen S, Adelsperger J, Okabe R, Coburn A, Moore S, Huntly BJ, Fabbro D, Anderson KC, Griffin JD, Gilliland DG (2005) FGFR3 as a therapeutic target of the small molecule inhibitor PKC412 in hematopoietic malignancies. Oncogene 24: 8259-8267

Chesi M, Brents LA, Ely SA, Bais C, Robbiani DF, Mesri EA, Kuehl WM, Bergsagel PL (2001) Activated fibroblast growth factor receptor 3 is an oncogene that contributes to tumor progression in multiple myeloma. Blood 97: 729-736

Chesi M, Nardini E, Brents LA, Schrock E, Ried T, Kuehl WM, Bergsagel PL (1997) Frequent translocation $\mathrm{t}(4 ; 14)(\mathrm{p} 16.3 ; \mathrm{q} 32.3)$ in multiple myeloma is associated with increased expression and activating mutations of fibroblast growth factor receptor 3. Nat Genet 16: 260-264

Chesi M, Nardini E, Lim RS, Smith KD, Kuehl WM, Bergsagel PL (1998) The $t(4 ; 14)$ translocation in myeloma dysregulates both FGFR3 and a novel gene, MMSET, resulting in IgH/MMSET hybrid transcripts. Blood 92: $3025-3034$ demonstrated by a decreased Ki-67 staining, but there was no evidence of apoptosis. Tumours regained their proliferative capacity following withdrawal of treatment both in vitro and in vivo and there was no change in proliferative or apoptotic indices after withdrawal of treatment. As tumour regression was not observed and PD173074 acted in a cytostatic rather than a cytotoxic manner it will be necessary to investigate how FGFRtargeted therapies can cooperate with standard treatments or other targeted agents.

Despite successfully demonstrating an in vivo effect of FGFR3 inhibition in three UC-derived xenografts, few UC cell lines are tumorigenic in immunocompromised mice. Improved in vivo models are urgently required to test the in vivo effect of FGFR inhibition in other cell lines, particularly FGFR3 mutant cell lines.

In conclusion, we have validated wild-type and mutant FGFR3 and WT FGFR1 as valid therapeutic targets for both muscleinvasive and superficial UC. Development of FGFR-targeted therapy (FGFR3 and/or FGFR1) for clinical use is therefore justified, with a possible future role as a 'maintenance' treatment following other modalities, such as surgery, cytotoxic drugs or radiation. Additional investigations are required to determine suitable predictive biomarkers to identify subgroups of patients for whom such therapies may be beneficial, for example according to FGFR1/3 expression levels and FGFR3 and RAS mutation status.

\section{ACKNOWLEDGEMENTS}

This work was supported by Cancer Research UK Grants C6228/ A5569 and C6228/A5437.

Supplementary Information accompanies the paper on British Journal of Cancer website (http://www.nature.com/bjc) di Martino E, L'Hote CG, Kennedy W, Tomlinson DC, Knowles MA (2009) Mutant fibroblast growth factor receptor 3 induces intracellular signaling and cellular transformation in a cell type- and mutation-specific manner. Oncogene 28: 4306-4316

Gomez-Roman JJ, Saenz P, Molina M, Cuevas Gonzalez J, Escuredo K, Santa Cruz S, Junquera C, Simon L, Martinez A, Gutierrez Banos JL, Lopez-Brea M, Esparza C, Val-Bernal JF (2005) Fibroblast growth factor receptor 3 is overexpressed in urinary tract carcinomas and modulates the neoplastic cell growth. Clin Cancer Res 11: 459-465

Grand EK, Chase AJ, Heath C, Rahemtulla A, Cross NC (2004) Targeting FGFR3 in multiple myeloma: inhibition of $\mathrm{t}(4 ; 14)$-positive cells by SU5402 and PD173074. Leukemia 18: $962-966$

Holmang S, Hedelin H, Anderstrom C, Johansson SL (1995) The relationship among multiple recurrences, progression and prognosis of patients with stages $\mathrm{Ta}$ and $\mathrm{T} 1$ transitional cell cancer of the bladder followed for at least 20 years. $J$ Urol 153: $1823-1826$

Intini D, Baldini L, Fabris S, Lombardi L, Ciceri G, Maiolo AT, Neri A (2001) Analysis of FGFR3 gene mutations in multiple myeloma patients with $\mathrm{t}(4 ; 14)$. Br J Haematol 114: 362-364

Jebar AH, Hurst CD, Tomlinson DC, Johnston C, Taylor CF, Knowles MA (2005) FGFR3 and Ras gene mutations are mutually exclusive genetic events in urothelial cell carcinoma. Oncogene 24: 5218-5225

Keats JJ, Reiman T, Maxwell CA, Taylor BJ, Larratt LM, Mant MJ, Belch AR, Pilarski LM (2003) In multiple myeloma, $t(4 ; 14)(\mathrm{p} 16 ; \mathrm{q} 32)$ is an adverse prognostic factor irrespective of FGFR3 expression. Blood 101: $1520-1529$

Kimura T, Suzuki H, Ohashi T, Asano K, Kiyota H, Eto Y (2001) The incidence of thanatophoric dysplasia mutations in FGFR3 gene is higher in low-grade or superficial bladder carcinomas. Cancer 92: $2555-2561$

Knowles MA (2006) Molecular subtypes of bladder cancer: Jekyll and Hyde or chalk and cheese? Carcinogenesis 27: 361-373 
Kurth KH, Denis L, Bouffioux C, Sylvester R, Debruyne FM, PavoneMacaluso M, Oosterlinck W (1995) Factors affecting recurrence and progression in superficial bladder tumours. Eur J Cancer 31 A: 1840 - 1846

Lee SH, Lopes de Menezes D, Vora J, Harris A, Ye H, Nordahl L, Garrett E, Samara E, Aukerman SL, Gelb AB, Heise C (2005) In vivo target modulation and biological activity of CHIR-258, a multitargeted growth factor receptor kinase inhibitor, in colon cancer models. Clin Cancer Res 11: $3633-3641$

Lopes de Menezes DE, Peng J, Garrett EN, Louie SG, Lee SH, Wiesmann M, Tang Y, Shephard L, Goldbeck C, Oei Y, Ye H, Aukerman SL, Heise C (2005) CHIR-258: a potent inhibitor of FLT3 kinase in experimental tumor xenograft models of human acute myelogenous leukemia. Clin Cancer Res 11: 5281-5291

Martinez-Torrecuadrada J, Cifuentes G, Lopez-Serra P, Saenz P, Martinez A, Casal JI (2005) Targeting the extracellular domain of fibroblast growth factor receptor 3 with human single-chain $\mathrm{Fv}$ antibodies inhibits bladder carcinoma cell line proliferation. Clin Cancer Res 11: 6280-6290

Miyake M, Ishii M, Koyama N, Kawashima K, Kodama T, Anai S, Fujimoto K, Hirao Y, Sugano K (2009) 1-tert-butyl-3-[6-(3,5-dimethoxyphenyl)-2-(4-diethylamino-butylamino)-pyrido[2,3-d]pyrimidin-7-yl]urea (PD173074), a selective tyrosine kinase inhibitor of FGFR3, inhibits cell proliferation of bladder cancer carrying the FGFR3 gene mutation along with up-regulation of p27/Kip1 and G1/G0 arrest. J Pharmacol Exp Ther 332: 795-802

Mohammadi M, Froum S, Hamby JM, Schroeder MC, Panek RL, Lu GH, Eliseenkova AV, Green D, Schlessinger J, Hubbard SR (1998) Crystal structure of an angiogenesis inhibitor bound to the FGF receptor tyrosine kinase domain. Embo J 17: 5896-5904

Mohammadi M, McMahon G, Sun L, Tang C, Hirth P, Yeh BK, Hubbard SR, Schlessinger J (1997) Structures of the tyrosine kinase domain of fibroblast growth factor receptor in complex with inhibitors. Science 276: 955-960

Ornitz DM, Itoh N (2001) Fibroblast growth factors. Genome Biol 2: REVIEWS3005

Parkin DM, Bray F, Ferlay J, Pisani P (2005) Global cancer statistics, 2002. CA Cancer J Clin 55: 74-108

Paterson JL, Li Z, Wen XY, Masih-Khan E, Chang H, Pollett JB, Trudel S, Stewart AK (2004) Preclinical studies of fibroblast growth factor receptor 3 as a therapeutic target in multiple myeloma. Br J Haemato 124: $595-603$

Plowright EE, Li Z, Bergsagel PL, Chesi M, Barber DL, Branch DR, Hawley RG, Stewart AK (2000) Ectopic expression of fibroblast growth factor receptor 3 promotes myeloma cell proliferation and prevents apoptosis. Blood 95: 992 -998

Qing J, Du X, Chen Y, Chan P, Li H, Wu P, Marsters S, Stawicki S, Tien J, Totpal K, Ross S, Stinson S, Dornan D, French D, Wang QR, Stephan JP, Wu Y, Wiesmann C, Ashkenazi A (2009) Antibody-based targeting of FGFR3 in bladder carcinoma and $t(4 ; 14)$-positive multiple myeloma in mice. J Clin Invest 119: 1216 - 1229

Sangar VK, Ragavan N, Matanhelia SS, Watson MW, Blades RA (2005) The economic consequences of prostate and bladder cancer in the UK. BJU Int 95: 59-63

Santra M, Zhan F, Tian E, Barlogie B, Shaughnessy Jr J (2003) A subset of multiple myeloma harboring the $\mathrm{t}(4 ; 14)(\mathrm{p} 16 ; \mathrm{q} 32)$ translocation lacks FGFR3 expression but maintains an IGH/MMSET fusion transcript. Blood 101: 2374-2376

Sibley K, Cuthbert-Heavens D, Knowles MA (2001a) Loss of heterozygosity at 4 p16.3 and mutation of FGFR3 in transitional cell carcinoma. Oncogene 20: 686-691
Sibley K, Stern P, Knowles MA (2001b) Frequency of fibroblast growth factor receptor 3 mutations in sporadic tumours. Oncogene 20: 4416-4418

Southgate J, Hutton KA, Thomas DF, Trejdosiewicz LK (1994) Normal human urothelial cells in vitro: proliferation and induction of stratification. Lab Invest 71: 583-594

Stein JP, Lieskovsky G, Cote R, Groshen S, Feng AC, Boyd S, Skinner E, Bochner B, Thangathurai D, Mikhail M, Raghavan D, Skinner DG (2001) Radical cystectomy in the treatment of invasive bladder cancer: longterm results in 1,054 patients. J Clin Oncol 19: 666-675

Tomlinson DC, Baldo O, Harnden P, Knowles MA (2007a) FGFR3 protein expression and its relationship to mutation status and prognostic variables in bladder cancer. J Pathol 213: $91-98$

Tomlinson DC, Hurst CD, Knowles MA (2007b) Knockdown by shRNA identifies S249C mutant FGFR3 as a potential therapeutic target in bladder cancer. Oncogene 26: 5889-5899

Tomlinson DC, L'Hote CG, Kennedy W, Pitt E, Knowles MA (2005) Alternative splicing of fibroblast growth factor receptor 3 produces a secreted isoform that inhibits fibroblast growth factor-induced proliferation and is repressed in urothelial carcinoma cell lines. Cancer Res 65: $10441-10449$

Tomlinson DC, Lamont FR, Shnyder SD, Knowles MA (2009) Fibroblast growth factor receptor 1 promotes proliferation and survival via activation of the mitogen-activated protein kinase pathway in bladder cancer. Cancer Res 69: 4613-4620

Trudel S, Ely S, Farooqi Y, Affer M, Robbiani DF, Chesi M, Bergsagel PL (2004) Inhibition of fibroblast growth factor receptor 3 induces differentiation and apoptosis in $\mathrm{t}(4 ; 14)$ myeloma. Blood 103: $3521-3528$

Trudel S, Li ZH, Wei E, Wiesmann M, Chang H, Chen C, Reece D, Heise C Stewart AK (2005) CHIR-258, a novel, multitargeted tyrosine kinase inhibitor for the potential treatment of $\mathrm{t}(4 ; 14)$ multiple myeloma. Blood 105: $2941-2948$

Trudel S, Stewart AK, Rom E, Wei E, Li ZH, Kotzer S, Chumakov I, Singer Y, Chang H, Liang SB, Yayon A (2006) The inhibitory anti-FGFR3 antibody, PRO-001, is cytotoxic to $\mathrm{t}(4 ; 14)$ multiple myeloma cells. Blood 107: $4039-4046$

van Rhijn BW, Lurkin I, Radvanyi F, Kirkels WJ, van der Kwast TH, Zwarthoff EC (2001) The fibroblast growth factor receptor 3 (FGFR3) mutation is a strong indicator of superficial bladder cancer with low recurrence rate. Cancer Res 61: 1265-1268

WHO (2004) Pathology and Genetics of Tumours of the Urinary System and Male Genital Organs. IARC Press: Lyon

Workman P, Twentyman P, Balkwill F, Balmain A, Chaplin D, Double J, Embleton J, Newell D, Raymond R, Stables J, Stephens T, Wallace J (1998) United Kingdom Co-ordinating Committee on Cancer Research (UKCCCR) guidelines for the welfare of animals in experimental neoplasia (second edition). Br J Cancer 77: 1-10

Wu XR (2005) Urothelial tumorigenesis: a tale of divergent pathways. Nat Rev Cancer 5: 713-725

Xin X, Abrams TJ, Hollenbach PW, Rendahl KG, Tang Y, Oei YA, Embry MG, Swinarski DE, Garrett EN, Pryer NK, Trudel S, Jallal B, Mendel DB, Heise CC (2006) CHIR-258 is efficacious in a newly developed fibroblast growth factor receptor 3-expressing orthotopic multiple myeloma model in mice. Clin Cancer Res 12: $4908-4915$

(c) (P) This work is licensed under the Creative Commons (c) $\mathrm{BY}$ NC SA Attribution-NonCommercial-Share Alike 3.0 Unported License. To view a copy of this license, visit http://creativecommons. org/licenses/by-nc-sa/3.0/ 